\title{
Time interval since last test in a breast cancer screening programme: a case-control study in Italy
}

\author{
DOMENICO PALLI, ${ }^{1}$ MARCO ROSSELLI DEL TURCO, ${ }^{2}$ EVA BUIATTI, ${ }^{1}$ STEFANO \\ CIATTO, ${ }^{2}$ EMANUELE CROCETTI, ${ }^{1}$ AND EUGENIO PACI ${ }^{1}$ \\ From ${ }^{1}$ the Epidemiology Unit and ${ }^{2}$ the Breast Unit, Centro per lo Studio e la Prevénzione Oncologica, Firenze, \\ Italy.
}

\begin{abstract}
Study objective: To evaluate a population based screening programme for breast cancer.

Design: This was a case-control study of women dying of breast cancer between 1977 and 1987 who had been invited to take part in a screening programme.

Setting: Community based study of women aged between 40 and 70 years (total population about 35000 at 1981 census), living in 23 small towns near Florence, Italy.

Participants: 103 cases were identified from death certification, and 515 living controls (five per case) selected for year of birth and town of residence.

Measurements and main results: Screening history was obtained from computer archive. Sociodemographic information was obtained from town registry offices and directly from relatives of the deceased and from the controls by postal questionnaire, and if necessary telephone or personal interview. Analysis was carried out on two age groups-40-49 years and 50+ years at diagnosisand considered the number of screening tests and the time interval since the last test, separately and together. In the older age group, women with at least one screening test in the previous $2 \frac{1}{2}$ years showed a $50 \%$ reduction in risk (odds ratio $0 \cdot 49,95 \%$ confidence interval $[\mathrm{CI}] 0 \cdot 25-0.95$ ). If they had also had another previous negative screen the risk was reduced to one third (odds ratio $0 \cdot 35,95 \% \mathrm{CI}$ $0 \cdot 14-0 \cdot 85$ ). There was a significant trend of decreasing risk with increasing number of screens in older women. No clear evidence of a similar protective effect was shown for women in the 40-49 year age group.

Conclusions: A significant protective effect of the screening programme is evident in older women but not in younger ones. The data do not allow an assessment of optimal screening interval because of the small number of previously screened cases.
\end{abstract}

A screening programme for the early diagnosis of breast cancer, currently under way in the Province of Florence and involving the female population aged between 40 and 70 , was started in 1970 , immediately after the preliminary results of the HIP randomised study in New York. ${ }^{1}$ Since then it has progressively involved 23 municipalities around Florence. These are grouped under three USLs (local health authorities), and are mostly located in the hill or mountain areas which are particularly disadvantaged with regard to access to breast diagnostic facilities. In four other small towns, the programme was stopped in the early 1970s because of organisational problems.

The programme is run by a centre located in Florence (Centre for the Study and Prevention of
Oncological diseases: CSPO) which runs other cancer screening programmes as well in cooperation with the local health authorities.

Screening is based on a single first level test-double view mammography. The whole resident female population in the age group 40-70 years (33 075 women at the last national census in 1981) is invited by mail using the registry lists provided from time to time by the individual town councils. Invitations to undergo mammography are currently issued about every two years, though previously the interval was longer. On average, in the period 1970-1987, the interval between two succeeding invitations has been around $\mathbf{3 0}$ months.

Mammographies are carried out in two mobile units 
(specially equipped vans), in which the mammographs are installed. These self driven units, moving from town to town, are operated by radiographers provided by CSPO and by experienced nurses from the local health authority. A form is filled for each participating woman, so that clinical and demographic information can be collected. The development and interpretation of the radiograms are carried out at the CSPO centre in Florence.

Physical examination is reserved for cases selected on the basis of symptoms (with the exception of pain alone) or radiological signs. The physical examination and any other necessary diagnostic test (in particular radiological examinations, or cytology of nipple discharge or fine needle aspirate) are always carried out in the CSPO breast clinic.

The results of a first case-control study, carried out by us and published recently, ${ }^{2}$ showed a significant protective effect of the programme for women over 50 years. In younger women, within the age group 40-49 years, there was no such evidence of a protective effect. Briefly, the methodology chosen was that of a casecontrol study design, as in other European studies; ${ }^{34}$ the cases were defined as women who had died of breast cancer, who were resident in the screening area and who were first diagnosed after the start of the programme itself (after at least the first invitation). The study considered 57 women who died in the period 1977-84 in the two USLs (11 and 18) and for whom registered information on the death certificates was available at that time.

The public health planning implications of the published results have prompted the updating of the study to include cases relating to the years 1985-87, and the enlargement of the area studied to include all 23 municipalities currently participating in the programme. The collection of information about a set of additional variables, considered as potential confounders, was planned in order to make the analysis more reliable.

The larger sample size of the study has also allowed us to consider in more depth the definition of the "exposure" (participation in the programme) not only in quantitative terms (number of mammographies) but also in relation to temporal factors (interval since last examination). These factors may be important for several reasons. For example in a situation where subjects may have been screened as long ago as 10 or more years before the valid date, a simple analysis of the type "women never screened/women screened at least once" could be insufficient. The same type of analysis performed according to the number of mammographies undergone could be potentially confounded by the fact that the time interval since last test for subjects who have undergone a greater number of examinations tends to be shorter than for subjects who have undergone only one examination. The low relative risk, shown in the previous study, for women over 50 with at least two mammographies (as compared with only one) could simply have been due to the fact that they had undergone the last examination more recently.

In the 23 towns included in the present study the time interval between the start of the programme and the end of the period considered varies from a minimum of 6 years up to a maximum of 17 years.

\section{Methods}

\section{CASES}

Based on death certificates, we identified a series of 103 cases of death from breast cancer in the period 1977-1987, in the area covered by the screening programme. The diagnosis, according to the available clinical records, had been made after at least a first invitation to the programme and within 3 years of the last invitation (usually at 70 years of age). No attempt was made to identify any women who might have died from breast cancer but where no mention of it was included on the death certificate. According to the age at the exact date of diagnosis, there were 28 cases in the्ष 40-49 year category ( $40-44$ years: 10 cases; $45-49$ : 18 cases) and the other 75 were in the over 50 yeap category (50-54: 14 cases; 55-59: 17 cases; 60-64: 1T cases; 65-69: 14 cases; 70+: 13 cases).

Nineteen cases were recorded as screen detectede eight in the 40-49 age group (four at a first test and four at a repeat test) and 11 in the older group (six at a? first test and five at a repeat test).

\section{CONTROLS}

Five living women were identified for each case. They were matched strictly according to town of residence and year of birth. The screening history information for each woman was collected from the computerised archives at CSPO, while other demographic data were found at the town registry offices, the aim being to reduce comparability problems arising from interviews involving surviving relatives of cases opposed to the women themselves in the control group. Overall 515 women were identified and considered as controls.

The mammographic examinations carried out on them within the screening programme were considered only up until the diagnosis date of the case with whom they were matched.

\section{SOURCE OF INFORMATION}

For each subject the information about the screening history until the date of diagnosis of the case in each matched set was collected from the computerised archives available at CSPO. 
Despite problems of comparability already mentioned, it was decided to investigate further the role of potential confounding variables by collecting additional information through a self administered postal questionnaire. A prepaid envelope was enclosed and a reminder with another copy of the questionnaire was sent if there was no reply after 4 weeks. For all the cases the questionnaire was sent to the last known address. The surviving relatives of the cases and the living controls were contacted by telephone or personally at their address when no answer was received. Overall the compliance to the questionnaire (by mail, telephone or interview) was over $98 \%$.

The variables considered in the questionnaire were selected according to their potential role as confounders and for their ability to confirm correct reporting by the relatives: number of children, age at first birth, occupation of the woman, occupation of the spouse, level of education, family history of breast cancer (mother and/or sister).

Other information was collected from the computerised archive available at CSPO for cervical cytology and mammographies performed outside the screening programme, at the self referral Florence breast clinic.

\section{ANALYSIS}

In the analyses of all the data in this study, we considered separately the number of examinations carried out and the time interval since the last test, and we also considered these two aspects together (categorised as follows: "number of examinations", 1 or 2+; "interval since last test", below or above 30 months, that is the average period between two succeeding rounds).

The interval of 30 months was calculated backward from the exact date of diagnosis for each case (and her matched controls); screen detected cases therefore fall into the "screened less than 30 months before" category, together with interval cases diagnosed in the first $2 \frac{1}{2}$ years following a test. Only clinically detected cases with a last screening test more than 30 months before the diagnosis fall in the other category.

The analysis was carried out with a conditional logistic model, utilising the PHGLM procedure in the "SAS" statistical packages and the IBM 3083 mainframe available at the Regional Tuscany Council. Crude odds ratios (conditional logistic model without confounding variables) and adjusted odds ratios with their $95 \%$ confidence intervals $(\mathrm{CI})$ were estimated and presented in the tables. Only adjusted odds ratios are presented in the results section and considered in the discussion.

Potential confounding variables were categorised as follows:

Number of children: $0,1-2$ and $3+$
Age at first birth: nulliparae, less than 30 years, more than 30 years

Civil status: ever married/never married

Years of education: less than 8 years $/ 8$ years or more

Occupation ("highest", woman or spouse): manual/clerical

Place of birth: Florence district/elsewhere

Family history of breast cancer: positive/negative Screening history for cervical cancer (Pap smears): $0-1 / 2+$

Self referred breast clinic mammographies: at least $1 /$ none.

The results are presented separately for two age groups, 40-49 years and over 50 years, according to the age at diagnosis of the case in each matched set.

\section{Results}

Table 1 lists the 23 small towns involved in the programme, the resident female population in the 40-69 age group at the last national census (October 1981), the starting date of the service and the number of periodic rounds completed by December 311987. Table 1 also shows the average response to the invitation in the different towns; on average, this was around $52 \%$, remaining quite constant but with a slight indication of a decrease over time.

A simple dichotomous analysis of ever versus never screened women reveals, as expected, a protective effect of screening, although the effect is weaker in the 40-49 year age group (table 2). Overall, considering the two age groups together, the adjusted odds ratio is $0.53(95 \%$ CI $0.33-0.85)$.

After considering the number of screening tests, the estimates presented in table 3 show, in the older age group, a reduction in risk of about $40 \%$ (odds ratio $0.62,95 \%$ CI $0 \cdot 32-1 \cdot 19$ ) for women screened only once; this reduction in risk reaches $60 \%$ for those screened at least twice (odds ratio $0.40,95 \%$ CI $0 \cdot 19-0.82$ ). A significant trend of decreasing risk with an increasing number of screening tests was present $(\mathrm{p}=0.01)$.

In the 40-49 year age group the results do not show this trend: for women screened at least twice the relative risk is greater than 1 (odds ratio $1 \cdot 18,95 \% \mathrm{CI}$ $0 \cdot 31-4 \cdot 47)$.

The results of considering the interval since the last test carried out in the programme, again using never screened women as the reference category, are presented in table 4 . In the younger age group (40-49 years) there was no evidence of a trend of decreasing risk for a decreasing interval since last test (interval longer or shorter than $\mathbf{3 0}$ months, which is the average interval between two succeeding rounds of the 
Table 1 Towns in the Florence District covered by the breast cancer screening programme: year of start of the programme, number of resident women at last national census (October 1981), number of screening rounds carried out at the end of 1987 and average percentage of attendance on the whole period considered.

\begin{tabular}{|c|c|c|c|c|c|}
\hline$U S L$ & Town & Year of start & $\begin{array}{l}\text { Resident women } \\
(40-70)\end{array}$ & Number of rounds & $\begin{array}{l}\text { Average attendance } \\
\%\end{array}$ \\
\hline 11 & $\begin{array}{l}\text { Barberino M.Llo } \\
\text { Borgo S.Lorenzo } \\
\text { Dicomano } \\
\text { Firenzuola } \\
\text { Londa } \\
\text { Marradi } \\
\text { Palazzuolo Senio } \\
\text { Pelago } \\
\text { Pontassieve } \\
\text { Rufina } \\
\text { S. Godenzo } \\
\text { S. Piero Sieve } \\
\text { Scarperia } \\
\text { Vicchio }\end{array}$ & $\begin{array}{l}1978 \\
1971 \\
1974 \\
1970 \\
1975 \\
1970 \\
1970 \\
1976 \\
1980 \\
1975 \\
1974 \\
1974 \\
1976 \\
1976\end{array}$ & $\begin{array}{r}1535 \\
2780 \\
758 \\
1043 \\
205 \\
799 \\
246 \\
1331 \\
3726 \\
1073 \\
238 \\
654 \\
930 \\
1111\end{array}$ & $\begin{array}{l}5 \\
6 \\
6 \\
7 \\
6 \\
7 \\
7 \\
7 \\
5 \\
3 \\
5 \\
6 \\
6 \\
5 \\
5\end{array}$ & $\begin{array}{l}61 \\
57 \\
57 \\
51 \\
53 \\
46 \\
78 \\
42 \\
50 \\
54 \\
44 \\
53 \\
71 \\
69\end{array}$ \\
\hline $10 \mathrm{H}$ & $\begin{array}{l}\text { Barberino V. Elsa } \\
\text { Greve } \\
\text { S. Casciano } \\
\text { Tavarnelle }\end{array}$ & $\begin{array}{l}1981 \\
1972 \\
1970 \\
1976\end{array}$ & $\begin{array}{r}635 \\
2107 \\
3033 \\
1196\end{array}$ & $\begin{array}{l}3 \\
6 \\
6 \\
5\end{array}$ & $\begin{array}{l}46 \\
40 \\
43 \\
43\end{array}$ \\
\hline 18 & $\begin{array}{l}\text { Castelfiorentino } \\
\text { Certaldo } \\
\text { Gambassi } \\
\text { Montaione } \\
\text { Montespertoli }\end{array}$ & $\begin{array}{l}1977 \\
1973 \\
1975 \\
1974 \\
1973\end{array}$ & $\begin{array}{r}3502 \\
3163 \\
771 \\
622 \\
1617\end{array}$ & $\begin{array}{l}4 \\
5 \\
6 \\
6 \\
7\end{array}$ & $\begin{array}{l}62 \\
63 \\
54 \\
52 \\
37\end{array}$ \\
\hline Total & & & 33075 & & $52 \%$ \\
\hline
\end{tabular}

USL $=$ local health authority

Table 2 Distribution of cases and controls and estimates of crude and adjusted odds ratios (conditional logistic model) by age at diagnosis (40-49 years and 50+) according to the participation in the screening programme (never/ever); $95 \%$ confidence intervals (CI) for the adjusted odds ratios.

\begin{tabular}{llllll}
\hline $\begin{array}{l}\text { Age at diagnosis } \\
\text { (years) }\end{array}$ & $\begin{array}{l}\text { Participation in } \\
\text { the programme }\end{array}$ & Cases/controls & Crude odds ratio & Adjusted odds ratio & $95 \%$ CI \\
\hline $40-49$ years & $\begin{array}{l}\text { Never } \\
\text { Ever }\end{array}$ & $11 / 38$ & $1^{*}$ & $1^{*}$ & 0.63 \\
& Total & $17 / 102$ & 0.55 & & $(0 \cdot 24-1 \cdot 64)$ \\
$50+$ years & $28 / 140$ & $37 / 122$ & $1^{*}$ & 0.51 & $(0 \cdot 29-0 \cdot 89)$ \\
& Never & $38 / 253$ & 0.48 & & \\
\hline
\end{tabular}

* reference category

programme). Older women ( $50+$ years) with their last examination in the previous 30 months showed a significant reduction in risk of about $50 \%$ (odds ratio $0.49,95 \%$ CI $0.25-0.95$ ); on the other hand women examined more than $\mathbf{3 0}$ months before showed a similar but statistically not significant reduction in risk when compared to never screened women.

The data were then analysed to evaluate simultaneously the effects of the number of screening tests and the interval since the last test. In the younger age group there was no evidence of a protective effect of participation in the screening programme, even for women examined in the last 30 months and with at least one other previous test (table 5). In the older age group (table 6), when the last test had been carried out more than $\mathbf{3 0}$ months before the date of diagnosis, there is limited evidence of a protective effect. The reduction in risk was around $50 \%$ for women screened 
Table 3 Distribution of cases and controls and estimates of crude and adjusted odds ratios (conditional logistic model) by age at diagnosis (40-49 years and 50+) according to the number of screening examinations (0, 1 or 2+); 95\% confidence intervals (CI) for the adjusted odds ratios and $\chi^{2}$ test for trend.

\begin{tabular}{|c|c|c|c|c|c|}
\hline $\begin{array}{l}\text { Age at diagnosis } \\
\text { (years) }\end{array}$ & $\begin{array}{l}\text { Number of } \\
\text { screening tests }\end{array}$ & Cases/controls & Crude odds ratio & Adjusted odds ratio & $95 \% C I$ \\
\hline $40-49 t$ & $\begin{array}{l}0 \\
1 \\
2+\end{array}$ & $\begin{array}{r}11 / 38 \\
9 / 67 \\
8 / 35\end{array}$ & $\begin{array}{l}1^{*} \\
0.46 \\
0.87\end{array}$ & $\begin{array}{l}1^{*} \\
0 \cdot 51 \\
1 \cdot 18\end{array}$ & $\begin{array}{c}\overline{(0 \cdot 18-1 \cdot 42)} \\
(0 \cdot 31-4 \cdot 47)\end{array}$ \\
\hline $50+\mp$ & $\begin{array}{l}0 \\
1 \\
2+\end{array}$ & $\begin{array}{l}37 / 122 \\
20 / 111 \\
18 / 142\end{array}$ & $\begin{array}{l}1^{*} \\
0 \cdot 61 \\
0 \cdot 36\end{array}$ & $\begin{array}{l}1^{*} \\
0.62 \\
0.40\end{array}$ & $\begin{array}{c}\overline{ } \\
(0 \cdot 32-1 \cdot 19) \\
(0 \cdot 19-0 \cdot 82)\end{array}$ \\
\hline
\end{tabular}

* reference category

$+\chi^{2}$ test for trend: 0.0 (NS)

$\mp \chi^{2}$ test for trend: $6.5(p=0.01)$

Table 4 Distribution of cases and controls and estimates of crude and adjusted odds ratios (conditional logistic model) by age at diagnosis (40-49 years and 50+) according to the interval since last screening test carried out in the programme (never screened, last test more than 30 months before and last test less than 30 months before); $95 \%$ confidence intervals (CI) for the adjusted odds ratios.

\begin{tabular}{|c|c|c|c|c|c|}
\hline $\begin{array}{l}\text { Age at diagnosis } \\
\text { (years) }\end{array}$ & $\begin{array}{l}\text { Interval since } \\
\text { last test }\end{array}$ & Cases/controls & Crude odds ratio & Adjusted odds ratio & $95 \% C I$ \\
\hline $40-49$ & $\begin{array}{l}\text { Never screened } \\
30+\text { months } \\
<30 \text { months }\end{array}$ & $\begin{array}{r}11 / 38 \\
3 / 17 \\
14 / 85\end{array}$ & $\begin{array}{l}1^{*} \\
0.59 \\
0.55\end{array}$ & $\begin{array}{l}1^{*} \\
0 \cdot 77 \\
0 \cdot 65\end{array}$ & $\begin{array}{c}-\overline{14}-4 \cdot 14) \\
(0 \cdot 25-1 \cdot 75)\end{array}$ \\
\hline $50+$ & $\begin{array}{l}\text { Never screened } \\
30+\text { months } \\
<30 \text { months }\end{array}$ & $\begin{array}{l}37 / 122 \\
16 / 99 \\
22 / 154\end{array}$ & $\begin{array}{l}1^{*} \\
0.53 \\
0.45\end{array}$ & $\begin{array}{l}1^{*} \\
0 \cdot 52 \\
0.49\end{array}$ & $\begin{array}{l}\overline{-} \\
(0.25-1.09) \\
(0.25-0.95)\end{array}$ \\
\hline
\end{tabular}

* reference category

Table 5 Women 40-49 years of age (at diagnosis): Distribution of cases and controls according to the number of screening mammographies $(0,1$ or $2+)$ and to the interval since last screening test (never screened, less than 30 months and 30 months or more). Odds ratio (OR) for matched data adjusted for the confounders in the conditional logistic model with $95 \%$ confidence intervals (CI).

Never screened*

Cases $11 \quad$ Controls 38

Screened

Screening mammographies

\begin{tabular}{|c|c|c|c|c|c|c|}
\hline \multirow[b]{2}{*}{ Interval since last test (months) } & \\
\hline & I screen & $O R$ & $95 \% \mathrm{CI}$ & $2+$ screens & $O R$ & $95 \% C I$ \\
\hline$<30$ & $6 / 51 t$ & 0.40 & $0 \cdot 12-1 \cdot 30$ & $8 / 34 t$ & $1 \cdot 46$ & $0.36-5.93$ \\
\hline
\end{tabular}

* reference category

t cases/controls

only once or at least twice, in comparison to never screened women. However if the last test was carried out less than 30 months before the date of diagnosis, the reduction in risk was very strong: around $65 \%$ for women with at least one other previous screening test (odds ratio $0 \cdot 35,95 \% \mathrm{CI} 0 \cdot 14-0 \cdot 85$ ). For women 
Table 6 Women older than 50 years (at diagnosis): Distribution of cases and controls according to the number of screening mammographies $(0,1$ or $2+)$ and to the interval since last mammography (never screened, less than 30 months and more than 30 months). Odds ratios (OR) for matched data and adjusted for the confounders in the conditional logistic model with $95 \%$ confidence intervals (CI).

Never screened ${ }^{*}$

Cases $37 \quad$ Controls 122

\begin{tabular}{|c|c|c|c|c|c|c|}
\hline \multirow[b]{3}{*}{ Interval since last test (months) } & \multicolumn{5}{|c|}{ Screened } & \multirow[b]{3}{*}{$95 \% C I$} \\
\hline & \multicolumn{5}{|c|}{ Screening mammographies } & \\
\hline & 1 screen & $O R$ & $95 \% C I$ & $2+$ screens & $O R$ & \\
\hline$<30$ & $12 / 68 t$ & 0.66 & $0.26-1.65$ & $10 / 86 t$ & 0.35 & $0.14-0.85$ \\
\hline$\geqslant 30$ & $8 / 43 t$ & 0.53 & $0.21-1.35$ & $8 / 56 t$ & 0.46 & $0 \cdot 17-1 \cdot 22$ \\
\hline
\end{tabular}

* reference category

† cases/controls

screened only once but in the recent past (first test within the last 30 months) the reduction in risk was also evident, at about $30 \%$, but the estimate was rather unstable (odds ratio $0 \cdot 66 ; 95 \%$ CI 0.26-1.65).

\section{Discussion}

Adjustment for several potential confounders, on the basis of the information collected following a rigid protocol (a first postal questionnaire, a reminder after a few weeks, telephone contacts or a final personal interview) did not substantially affect the estimates of the protective effect of screening participation. The differences between crude and adjusted odds ratios in this analysis were always very small.

The present results, in agreement with our previous study, do not show any significant evidence of a protective effect for younger women attending the programme, even after considering the interval since the last test and the total number of tests performed. A first explanation (apart from the small number of women in this age group) could be the lower sensitivity of mammography in the younger women, probably due to the higher "density" of breast tissues. ${ }^{6}$

It is also possible, however, that the interval between two screening rounds in this programme (2-3 years, 30 months on the average) is too long to produce any protective effect for screened women in the age group under 50 years. The Swedish "two county" randomised trial recently estimated that in this age group the incidence rate in the second year after a screening test is already $70 \%$ of the rate observed in the control group. ${ }^{7}$

The results of another Swedish study, the randomised trial in $\mathrm{Malmo}^{8}$ showed no effect in women younger than 55 years of age. Also the UK trial, in which women in the 45-64 age group were invited, showed only a slight protective effect, about $20 \%$ reduction in risk across all ages, falling short of statistical significance; ${ }^{9}$ no age specific data were available.

The average time interval between the start of the programme and the end of the period considered in $\mathbb{D}$ this study (December 1987) is rather long and a longer $\frac{\overrightarrow{\mathrm{D}}}{\mathrm{O}}$ latency of the appearance of the protective effect in this younger group, as suggested by the HIP study, ${ }^{10}$ seems an unlikely explanation.

Our results according to the analysis "ever versus never screened" show a significant protective effectso overall and in the older age group. However such a simple approach is unsatisfactory, in particular when the follow up becomes very long. After considering the number of screening tests, it is shown that older women screened at least twice are significantly protected; a trend of decreasing risk with an increasing number of tests is evident. It is clear, however, that temporal factors should also be taken into account.

In the older age group, the women examined in the previous 30 months showed a risk of dying from breast cancer in the following years which was significantly lower than in never screened women. This reduction in risk was more evident for those women with at least one other previous screening test. These results suggest an independent effect of both the "interval since last test" and of the "number of tests" carried out in the programme (only one/two or more).

According to the analysis presented in table 6 , the major issue is the difference between the protective effect of a first single test and that of a repeat screening test (all women with two or more tests are considered together in this category): the two categories could actually be defined as women with a "prevalence" screen and women with a "repeat" screen in the last 30 months. 
The distribution of the time interval already spent in the preclinical detectable phase, at the moment of the diagnosis will be quite different for cancers detected at a prevalence screen compared to the same distribution for cancers detected at a repeat screen. In the first case the distribution will tend to be skewed to the right since most of the prevalent cancers have already spent a long period in the preclinical phase and are usually advanced; therefore the lead time (the remaining part of the preclinical detectable phase) is rather short.

At a repeat screen (depending on the interval since the previous negative test) the distribution of time intervals spent in the preclinical detectable phase will tend to be skewed to the left: most of these cancers are less advanced, having spent a shorter period of time in the preclinical phase than the interval itself (only false negatives at the previous screen, by definition, have spent a period longer than the screening interval in the preclinical phase). The average lead time, if the interval between the two succeeding screening tests is sufficiently short, will tend to be longer, in comparison to prevalent screen detected cases. The proportion of advanced cancers detected at a repeat screen will also depend on the age distribution of the screened population, being related to the sensitivity of the test. ${ }^{7}$

It seems reasonable that cases with a longer lead time (because of the shorter time spent in the preclinical phase when detected at a repeat screen) should have a lower risk of dying from breast cancer in comparison to cases with a shorter lead time (detected at a prevalence screen) and to cases with no lead time (clinically detected cancers in never screened women). Also interval cancers have a lead time equal to zero, being clinically detected.

In this type of analysis, it is necessary to consider two methodological issues, potentially related to the evaluation of the true protective effect of the participation in the screening programme (only screen detected cases actually benefit from screening). (1) According to the interval since last test, in the category "less than $\mathbf{3 0}$ months", screen detected cases are considered together with interval cases; a subdivision of the "less than $\mathbf{3 0}$ months" category into two separate categories could provide additional information. (2) According to the number of screening tests, in the category " $2+$ " all subjects with two or more tests are considered together, independently of the time interval between the last test and the previous one (regular attenders and irregular attenders); the fact of having skipped a previous round can shift the distribution of lead time for cases detected at a repeat test.

Screen detected cases at a repeat test with a very long interval since previous negative test could show a risk very similar to screen detected cases at a first prevalence test; the time interval between the last test and the previous one (infinite for subjects never screened before) must be considered more important than the total number of tests performed.

It is evident therefore that both temporal aspects (time since last test and time between last test and the previous one) must be considered in order to analyse correctly the date from a case-control study in this field. It must be clear, however, that only the evaluation of the interval between the last test and the previous "negative" one could allow us to study the role of different intervals in breast cancer screening programmes with a case-control approach. Moreover such a study should be restricted to a cohort of women with at least an initial negative screening test. This was not possible in the present study due to the very small number of previously screened cases.

Further studies, possibly cooperative and multicentre, pooling already existing series, are needed for this purpose. No conclusion therefore can presently be drawn from our study on this particular issue.

The Florence District programme will be monitored with an ongoing case-control study identifying every year additional deceased cases in order to increase the sample size, particularly in the $40-49$ age group. Breast cancer screening for younger women must still be considered a research issue on which it is necessary to gain additional evidence before recommending it as a public health service.

The extension of the screening programme to the city of Florence has been planned. Women in the 40-49 years will not be invited but they will have free access to the self referral CSPO breast clinic. The "Florence Project", supported by the Local Health Authorities, will start at the end of 1989 , and the 60000 resident women in the 50-69 years age group will be invited every 2 years for double view mammography.

Address for correspondence and reprints: Domenico Palli, MD, Epidemiology Unit, CSPO, Viale Volta 171, 50131, Firenze, Italy.

This work was supported by a grant from O.E.R. (Osservatorio Epidemiologico Regionale-Regione Toscana).

\section{References}

${ }^{1}$ Shapiro S, Strax PH, Venet L. Periodic breast cancer screening in reducing mortality from breast cancer $J A M A$ 1971; 215: 1777-85.

2 Palli D, Rosselli del Turco M, Buiatti E, et al. A casecontrol study of the efficacy of a non-randomized breast cancer screening program in Florence (Italy). Int J Cancer 1986; 38: $501-4$. 
${ }^{3}$ Collette HJA, Day N, Rombach JJ, De Waard F. Evaluation of screening for breast cancer in a nonrandomized study (the Dom project) by means of a case-control study. Lancet 1984; i: 1224-6.

${ }^{4}$ Verbeek ALM, Hendriks JHCL, Holland R, Mravunac M, Sturmans F, Day NE. Reduction of breast cancer mortality through mass screening with modern mammography: first results of the Nijmegen project, 1975-1981. Lancet 1984; i: 1222-4.

${ }^{5}$ Harrell FE. The PHGLM procedure. In: SUGI Supplemental User's Guide, 1985 edition. Cary, NC: SAS Institute, 1985: 437-66.

${ }^{6}$ Rosselli del Turco M, Giannardi G, Villari N. The diagnostic efficacy of mammography and palpation in early detection of breast cancer. Tumori 1980; 66: 85-92.

${ }^{7}$ Tabar L, Faberberg G, Day NE, Holmberg L. What is the optimum interval between mammographic screening examinations? An analysis based on the latest results of the Swedish two-county breast cancer screening trial. Br J Cancer 1987; 55: 547-51.

${ }^{8}$ Andersson I, Aspegren K, Janzon L, et al. Mammographic screening and mortality from breast cancer: the Malmo mammographic screening trial. $\mathrm{Br} \mathrm{Med} J$ 1988; 297: 943-8.

${ }^{9}$ UK Trial of Early Detection of Breast Cancer Group. First results on mortality reduction in the UK trial of early detection of breast cancer. Lancet 1988; ii: 411-6.

${ }^{10}$ Habbema JDF, van Oortmarssen GH, van Putten DJ, Lubbe JT, van der Maas PJ. Age-specific reduction in breast cancer mortality by screening: an analysis of the results of the Health Insurance Plan of Greater New York study. J Natl Cancer Inst 1986; 77: 317-20.

Accepted for publication April 1989 